\title{
The role of the veterinarian in animal welfare Jan Ladewig
}

\author{
Address: Department of Large Animal Sciences University of Copenhagen, Grønnegårdsvej 8, 1870 Frederiksberg C, Denmark \\ Email: Jan Ladewig - jal@life.ku.dk
}

\begin{abstract}
from The role of the veterinarian in animal welfare. Animal welfare: too much or too little? The 2 Ist Symposium of the Nordic Committee for Veterinary Scientific Cooperation (NKVet)

Værløse, Denmark. 24-25 September 2007

Published: 19 August 2008

Acta Veterinaria Scandinavica 2008, 50(SuppI I):S5 doi:I0.I I86/I75I-0I47-50-SI-S5
\end{abstract}

This abstract is available from: http://www.actavetscand.com/content/50/SI/S5

(c) 2008 Ladewig; licensee BioMed Central Ltd.

For many veterinarians, animal welfare is a matter of animal health: As long as an animal is healthy, it is also happy. For the past forty years, however, behaviour biologists have shown repeatedly that, whereas poor health contributes to poor welfare, the opposite is not necessarily the case. There is more to good welfare than good health.

Numerous studies have shown that, despite many generations of selection for various traits, the behavioural repertoire of domestic animals is almost identical to that of their wild ancestors. A broiler chicken has a similar demand for dust bathing as a jungle fowl. A thoroughbred racehorse has the same demand for social contact as the Przwalski horse. These are just two of many other examples. Consequently, to ensure a certain level of welfare in our domestic animals, it is important that they are able to perform their species-specific behaviour beyond eating behaviour, drinking behaviour, eliminative behaviour and resting behaviour.

And that's where the controversy begins!

Which elements of the animal's ethogram are essential and which ones are not? Must a prey animal show flight behaviour regularly to be happy? Must a well-fed animal show foraging behaviour to be content? Is social contact through bars enough contact?

The controversy consists of, on the one side, practitioners or producers that need to house and manage animals in such a way that their production is productive and, on the other side, animal protection people or animal rights peo- ple who are against any "exploitation" of the domestic animals.

As with most issues, obviously the optimum lies somewhere in between these two extremes. We all have to compromise and so must our domestic animals. In return for regular food, water, shelter and medical care, the animals must give up some of their freedom. But how much they must give up, how restrictively we can keep them with good conscience, is a matter of dispute.

The veterinary profession plays a key role in the controversy in that it possesses a detailed knowledge of both camps. Practicing veterinarians and veterinary inspectors are in regular contact with the animals, either in the clinic or during visits to the farms, either to treat sick animals, to institute preventive measures, or to control that legislation is being followed. At the same time veterinarians possess (or should possess) the scientific background that enable them to judge the welfare of their patients and clients.

Public concern for the welfare of domestic animals is likely to increase in the future. At the present time behaviour biologists still struggle with the difficult task of "measuring happiness" in the animals. Similarly, programs for monitoring welfare in praxis are being developed in many countries. An important question in these developments is how the veterinary profession can best prepare itself for future challenges, both in the veterinary curriculum and in terms of continued education. 